\title{
Gemcitabine twice weekly as a radiosensitiser for the treatment of brain metastases in patients with carcinoma: a phase I study
}

\author{
A Maraveyas*,', J Sgouros', S Upadhyay², A-H Abdel-Hamid², M Holmes² and M Lind' \\ 'Department of Academic Oncology and University of Hull, Saltshouse Road, Hull HU8 9HE, UK; ${ }^{2}$ Department of Clinical Oncology, The Princess Royal \\ Hospital, Hull HU8 9HE, UK
}

\begin{abstract}
Conventional treatment for brain metastases (BM) is whole-brain radiotherapy (WBRT). Efficacy is poor. It might be increased by a potent radiosensitiser such as gemcitabine which is believed to cross the disrupted blood-brain barrier. Primary objective of this study was to determine the maximum tolerated dose (MTD) of twice weekly gemcitabine given concurrently with WBRT. Patients with BM from carcinoma were included. The dose of WBRT was $30 \mathrm{Gys}$ ( 10 daily fractions). Gemcitabine was given $2-4 \mathrm{~h}$ prior to WBRT on days I and 8 for the first cohort of patients and then on days I, 4, 8 and I I. Starting dose was $25 \mathrm{mg} \mathrm{m}^{-2}$, escalated by $12.5 \mathrm{mg} \mathrm{m}^{-2}$ increments. At least three patients were included per level. Dose limiting toxicity (DLT) was defined as grade 4 haematological or grade $\geqslant 3$ nonhaematological toxicity. A total of 25 patients were included; $74 \%$ had a PS I (ECOG). In all, 23 had non-small-cell lung cancer, six colorectal, four breast, two renal cell and one oesophageal carcinoma. A total of $92 \%$ had concurrent extracranial disease. Six had single BM, 13 had two or three BM and six multiple. Up to $50 \mathrm{mg} \mathrm{m}^{-2}$ (level 4) no DLT was observed. At $62.5 \mathrm{mg} \mathrm{m}^{-2}$, one out of six patients developed DLT (thrombocytopenia-bleeding). The next dose level $\left(75 \mathrm{mg} \mathrm{m}^{-2}\right.$ ) was abandoned after grade 4 bone marrow toxicity (fatal neutropenic sepsis) was seen in one out of two patients. So that the dose of $50 \mathrm{mg} \mathrm{m} \mathrm{m}^{-2}$ will be taken forward for further study.
\end{abstract}

British Journal of Cancer (2005) 92, 815-819. doi: 10.1038/sj.bjc.6602444 www.bjcancer.com

Published online 15 February 2005

(c) 2005 Cancer Research UK

Keywords: brain metastases; radiosensitisation; gemcitabine; phase I study

Brain metastases (BM) occur in $20-40 \%$ of cancer patients during the course of their illness and $50-75 \%$ of them have more than one metastasis (Patchel, 2003). Except for very few cases where surgery may be indicated, the mainstream accepted therapeutic modality is whole brain radiotherapy (WBRT). Gamma-knife radiosurgery and conformal radiotherapy are recent developments that may confer a prognosis improvement to selected patients mostly in cases of single $\mathrm{BM}$ and controlled extracranial disease. The prognosis of the vast majority of patients who develop $\mathrm{BM}$ is poor. The median survival for treated patients with WBRT is approximately 4 months and the 1-year survival only 12\% (Lagerwaard et al, 1999). Chemotherapy is not usually given and if the patient is actually receiving chemotherapy, it is often discontinued. This attitude has been fostered by the theoretical difficulty of drugs to pass the blood-brain barrier and achieve therapeutic significance in brain micrometastases. This however is probably not the case with macroscopic metastases. Brain metastases in patients with many chemosensitive tumours (e.g. testicular cancer, lymphoma, choriocarcinoma) are well known to respond to chemotherapy. A recent study by Postmus et al (2000) in patients with small-cell carcinoma and $\mathrm{BM}$ showed a $22 \%$ response rate to chemotherapy

\footnotetext{
* Correspondence: Dr A Maraveyas, Academic Department of Oncology, Princess Royal Hospital, Saltshouse Road/Hull, East Yorkshire HU8 9HE, UK; E-mail: A.Maraveyas@hull.ac.uk

Received 12 October 2004; revised 6 January 2005; accepted 6 January 2005; published online 15 February 2005
}

alone. However, the combination of chemotherapy and radiotherapy produced a $57 \%$ response rate and the control in the brain disease in these patients was longer than in patients who received only chemotherapy. A phase III study of early $v s$ late WBRT with concurrent cisplatin and vinorelbine in patients with non-smallcell lung cancer (NSCLC) and BM was reported by Robinet et al (2001). Patients were chemonaive and drugs were given at full dose. Patients were randomised to receive WBRT 30 Grays (Gy) in 10 fractions over 12 days after two cycles of chemotherapy or on days 1-12 concurrently with chemotherapy. The grade 3-4 toxicities were similar and specifically neurotoxicity and toxic deaths were comparable in both arms. The response rate to chemotherapy (as judged in the patients randomised to delayed WBRT) was $27 \%$. Many other studies have shown that BM from a number of primary sites can be equally chemosensitive as to areas outside the brain (Van den Bent, 2003). The problem of perceived resistance is probably due to the fact that $\mathrm{BM}$ usually develop as a late event in patients already treated with many agents to which resistance has already developed.

One of the most promising newer chemotherapeutic drugs is the bifluorinated analogue of cytarabine, gemcitabine. Gemcitabine, both as a single agent and in combination with cisplatin or other agents achieves a significant response rate in NSCLC, head and neck carcinoma, pancreatic, breast and gynaecologic cancer (Carmichael, 1998). This tends to be accompanied by a favourable toxicity profile.

Gemcitabine has also demonstrated activity in BM in patients with carcinoma. Gridelli et al (1999) evaluated the efficacy of the 
drug in 30 patients with NSCLC who had already received chemotherapy with a platinum compound. The authors observed six partial responses, and two of them were in patients with BM.

In a further study by Ceribelli et al (2003), again in patients with NSCLC but this time treated with cisplatin and gemcitabine, the overall response rates in the Arm of gemcitabine at the standard 30 min infusion (Arm A) and in the arm of gemcitabine at an infusion rate of $10 \mathrm{mg} \mathrm{m}^{-2} \mathrm{~min}^{-1}$ (Arm B) were $26 \%(95 \%$ confidence interval $(95 \% \mathrm{CI}), 10-42 \%)$ and $34 \%$ (95\% CI, $17-$ $52 \%)$, respectively. In the patients who happened to have $\mathrm{BM}$, it was interesting to note a high response rate (67\%) of BM in Arm B. Toxicity was tolerable and comparable in the two arms. As a radiosensitiser, gemcitabine has been used in patients with NSCLC, pancreatic cancer, head and neck cancer and cervical cancer. There are no data for the use of gemcitabine as a radiosensitiser in the setting of BM.

The aim of the current study was to find the maximum tolerated dose (MTD) of gemcitabine when given as a radiosensitiser on a twice weekly schedule to patients with $\mathrm{BM}$ from carcinoma.

\section{MATERIALS AND METHODS}

\section{Eligibility}

Patients with histologically or cytologically confirmed carcinoma and BM were eligible for the study provided that surgery was not an option. Eligibility criteria also included an Eastern Cooperative Oncology Group performance status of $0-2$ and age $\geqslant 18$ years. Adequate haematologic function was required: a white blood count of $\geqslant 3500$ cells $\mu \mathrm{l}^{-1}$, a platelet count of $\geqslant 100000 \mu \mathrm{l}^{-1}$, and a haemoglobin level of $\geqslant 10 \mathrm{~g} \mathrm{dl}^{-1}$. Also, serum bilirubin needed to be below two times the upper limit of normal (ULN), ALT and AST below three times ULN - ALT and AST could be elevated to five times ULN in patients with known metastatic disease in the liver and creatinine below two times ULN.

Previous chemotherapy was allowed up to second line as long as gemcitabine had not been used. Patients had to be stable on steroids. Patients with seizures who were not stable on antiepileptic medication were excluded. No previous radiotherapy to the brain of any form was allowed. No surgical procedure to the brain and no confusion was allowed (correctable confusion (hypercalcaemia, hyponatremia) with time to correct it and documented adequate mini-mental test scoring was allowed). For female subjects of childbearing potential, adequate contraception during and 3 months post-treatment was required. Patients with haemorrhagic metastases were excluded and patients allergic to contrast material either underwent MRI as baseline study or were excluded.

The protocol was approved by the Hull and East Yorkshire Hospitals Ethics Committee. Written informed consent was obtained from all patients prior to the participation in the study.

CT or MRI scan of the brain was necessary before the beginning of treatment. It was repeated if possible 1 month after the end of the treatment ( 6 weeks). Patients were withdrawn from the study if they developed sudden neurological deterioration indicating intracranial bleed, allergic reaction to the chemotherapy agent, development of infection allowing continuation of RT but not of chemotherapy and upon patient request.

\section{Treatment}

A conventional radiotherapy fractionation schedule was used ( $30 \mathrm{~Gy}$ in 10 fractions over 12 days). The radiotherapy to the whole brain was planned by simulation and given by parallel opposed right and left lateral portals using six megavoltage X-rays beams. Gemcitabine was given, as an intravenous infusion over $30 \mathrm{~min}$, $2-4 \mathrm{~h}$ prior to radiotherapy. If the absolute neutrophil count
(ANC) was $\geqslant 750$ cells $\mu \mathrm{l}^{-1}$, the platelet count was $\geqslant 100000 \mu \mathrm{l}^{-1}$ and the patient had no more than grade 2 nonhaematological toxicity, the full dose was delivered. With an ANC of $\geqslant 500$ cells $\mu \mathrm{l}^{-1}$ but $<750$ cells $\mu \mathrm{l}^{-1}$ and platelet count of $\geqslant 75000 \mu \mathrm{l}^{-1}$ but $<100000 \mu \mathrm{l}^{-1}, 75 \%$ of the dose was given. Gemcitabine dose was omitted if platelet count dropped below $75000 \mu \mathrm{l}^{-1}$, ANC dropped below 500 cells $\mu \mathrm{l}^{-1}$ or if the patient was experiencing grade 3 or greater nonhaematological toxicity.

The Folstein mini-mental test (Folstein et al, 1975) was undertaken at baseline and weekly while on treatment and 4weekly thereafter until the patient came off study due to progression. It was used as a tool to monitor the cognition of the patients and detect any potential side effects of the treatment to their neurocognitive performance, especially in those who achieved a radiological response or stabilisation of their brain disease.

\section{Study design}

The starting dose of gemcitabine was $25 \mathrm{mg} \mathrm{m}^{-2}$ on days 1 and 8 . The next level was $25 \mathrm{mg} \mathrm{m}^{-2}$ on days $1,4,8$ and 11 (Table 2).

For dose escalation, three assessable patients had to complete their treatment and the first post-treatment month without a dose limiting toxicity (DLT). Haematological toxicities were defined as DLT if they were grade 4 at WHO scale. All other toxicities were defined as DLT if they were grade $\geqslant 3$ at the WHO scale. If no DLT was experienced, then dose escalation could proceed and three patients were enrolled at the next dose level. If two or more patients experience DLT, then the MTD had been defined at this dose level. When one DLT was seen, an additional three assessable patients had to be accrued, and further escalation could occur if no additional DLT were seen. Once the MTD was established, the phase II dose level was defined as the dose level before MTD was reached.

\section{Response assessment}

Response was assessed by repeat CT or MRI scan of the brain 4 weeks after the end of the treatment. We determined response by using the response evaluation criteria in solid tumours group (RECIST) criteria (Therasse et al, 2000). Complete response (CR) was defined as disappearance of all target and nontarget tumour lesions and partial response (PR) as a $30 \%$ or greater decrease in the sum of the longest diameter of all target lesions together with stabilisation or decrease in size of nontarget lesions. Disease progression $(P D)$ required $a \geqslant 20 \%$ increase in the sum of the longest diameter of target lesions, an unequivocal increase in the nontarget lesions or appearance of any new lesions. Stable disease was defined as insufficient tumour shrinkage to qualify for PR and insufficient increase in tumour size to qualify for PD. It has to be noted that the study did not stipulate a further scan 4 weeks later (i.e. 8 weeks post-treatment ) to confirm response in responding patients.

\section{RESULTS}

\section{Patients characteristics}

Between February 2001 and July 2003, 25 patients were included in this phase I study. As shown in Table 1, the most common type of cancer was NSCLC, followed by colorectal and breast cancer. In all, $76 \%$ of patients had more than one brain metastasis and almost all of them had active malignant disease outside brain (92\%). All of them were on oral steroids (dexamethasone). The daily dose ranged from 2 to $16 \mathrm{mg}$ (median dose $12 \mathrm{mg} \mathrm{day}^{-1}$ ) and it remained stable while patients received the study treatment. Two patients were also on oral phenytoin $300 \mathrm{mg} \mathrm{day}^{-1}$. 


\section{Dose levels and toxicities observed}

Six different doses of gemcitabine were studied. Patients included at the first level of treatment had their gemcitabine doses once per week. All other patients received the chemotherapy drug twice weekly. Overall, 84 doses of gemcitabine were given and the median number per patient was four. Doses up to $37.5 \mathrm{mg} \mathrm{m}^{-2}$ were very well tolerated without any signs of significant toxicity. As it can be seen in Table 2 at the dose of $50 \mathrm{mg} \mathrm{m}^{-2}$, no DLT has occurred but four out of seven patients needed dose reduction during their treatment. The toxicity that caused dose reduction of the drug was in all cases thrombocytopenia grade 2 during the second week of treatment (third and/or fourth dose of gemcitabine).

At the dose of $62.5 \mathrm{mg} \mathrm{m}^{-2}$, one patient developed bonemarrow-related DLT. Neutropenia and thrombocytopenia grade

Table I Patient characteristics $(N=25)$

\begin{tabular}{|c|c|c|}
\hline \multirow[b]{2}{*}{ Variable } & \multicolumn{2}{|c|}{ Number of patients } \\
\hline & $n$ & $\%$ \\
\hline \multicolumn{3}{|l|}{ Age (years) } \\
\hline Median & 57 & - \\
\hline Range & $41-76$ & - \\
\hline \multicolumn{3}{|l|}{ Gender } \\
\hline Male & 15 & 60 \\
\hline Female & 10 & 40 \\
\hline \multicolumn{3}{|l|}{ Performance Status } \\
\hline 0 & 6 & 24 \\
\hline I & 18 & 72 \\
\hline 2 & । & 4 \\
\hline \multicolumn{3}{|l|}{ Type of cancer } \\
\hline NSCLC ${ }^{a}$ & 12 & 48 \\
\hline Colorectal & 6 & 24 \\
\hline Breast & 4 & 16 \\
\hline Other (renal cell and oesophageal) & 3 & 12 \\
\hline \multicolumn{3}{|l|}{ Number of brain metastases } \\
\hline I & 6 & 24 \\
\hline 2 or 3 & 13 & 52 \\
\hline 4 or more & 6 & 24 \\
\hline \multicolumn{3}{|l|}{ Extracranial disease } \\
\hline Yes & 23 & 92 \\
\hline No & 2 & 8 \\
\hline \multicolumn{3}{|l|}{ Previous chemotherapy } \\
\hline Yes & 12 & 48 \\
\hline No & 13 & 52 \\
\hline
\end{tabular}

${ }^{a} \mathrm{NSCLC}=$ non-small-cell lung cancer.
4 occurred in one of the first three patients treated at this dose. This patient suffered from oesophageal cancer and she was hospitalised but died during the second week of treatment from uncontrolled lower GI bleeding. No further DLTs were seen at this level, but one patient needed a dose reduction due to thrombocytopenia grade 2 and another one developed grade 3 thrombocytopenia after the end of treatment.

Two further patients were treated at the gemcitabine dose of $75 \mathrm{mg} \mathrm{m}^{-2}$ and one of them developed grade 4 neutropenia and fatal neutropenic sepsis immediately after the end of treatment. Haematological toxicities are summarised in Table 3. Given the experience at the previous dose level and the further toxicity seen in one patient at dose level $6\left(75 \mathrm{mg} \mathrm{m}^{-2}\right)$, it was decided that the MTD had been reached at dose level $5\left(62.5 \mathrm{mg} \mathrm{m}^{-2}\right)$ and the study of further patients at dose level 6 was abandoned. Therefore, dose level $4\left(50 \mathrm{mg} \mathrm{m}^{-2}\right)$ is the dose to be taken forward to a phase II study. At this dose level, four of seven patients needed dose adjustment of the third and or fourth dose but no greater than grade 2 bone marrow toxicity was noted.

No significant nonhaematological toxicities were observed at any dose level. In particular, no deterioration of the cognitive function of the responding patients was found by using the minimental status examination (MMSE). At the beginning of treatment, the average score of patients in the MMSE was 28.5 (range 24-30) with 30 being the maximum score that someone can achieve in the examination. Just after the completion of the treatment the mean score was 28.25 (range 25-30), while at 3 months the median score for six patients who responded to treatment was 29.6 (range 28-30).

Table 2 Dose limiting toxicities (DLTs) and occurrence of toxicities necessitating dose reduction or dose omission by the seven dose levels of gemcitabine tested

\begin{tabular}{|c|c|c|c|}
\hline $\begin{array}{l}\text { Gemcitabine } \\
\text { dose }\end{array}$ & $\begin{array}{c}\text { Number of } \\
\text { patients treated }\end{array}$ & $\begin{array}{l}\text { Number of } \\
\text { patients needed } \\
\text { reduction or } \\
\text { omission of at } \\
\text { least one dose }\end{array}$ & $\begin{array}{c}\text { Number of } \\
\text { patients with a } \\
\text { DLT }\end{array}$ \\
\hline $25 \mathrm{mg} \mathrm{m}^{-2}$ weekly & 4 & 0 & 0 \\
\hline $\begin{array}{l}25 \mathrm{mg} \mathrm{m}^{-2} \text { twice } \\
\text { weekly }\end{array}$ & 3 & 2 & 0 \\
\hline $\begin{array}{l}37.5 \mathrm{mg} \mathrm{m}^{-2} \text { twice } \\
\text { weekly }\end{array}$ & 3 & 0 & 0 \\
\hline $\begin{array}{l}50 \mathrm{mg} \mathrm{m}^{-2} \text { twice } \\
\text { weekly }\end{array}$ & 7 & 4 & 0 \\
\hline $\begin{array}{l}62.5 \mathrm{mg} \mathrm{m}^{-2} \text { twice } \\
\text { weekly }\end{array}$ & 6 & 2 & । \\
\hline $\begin{array}{l}75 \mathrm{mg} \mathrm{m}^{-2} \text { twice } \\
\text { weekly }\end{array}$ & 2 & । & । \\
\hline
\end{tabular}

Table 3 Haematological toxicities as occurred among 25 treated patients by the seven dose levels of gemcitabine tested

\begin{tabular}{|c|c|c|c|c|c|c|c|}
\hline \multirow[b]{2}{*}{ Gemcitabine dose } & \multirow[b]{2}{*}{ Number of patients treated } & \multicolumn{3}{|c|}{ Neutropenia (number of patients) } & \multicolumn{3}{|c|}{ Thrombocytopenia (number of patients) } \\
\hline & & Grade 2 & Grade 3 & Grade 4 & Grade 2 & Grade 3 & Grade 4 \\
\hline $25 \mathrm{mg} \mathrm{m}^{-2}$ weekly & 4 & । & 0 & 0 & । & 0 & 0 \\
\hline $25 \mathrm{mg} \mathrm{m}^{-2}$ twice weekly & 3 & 0 & 0 & 0 & 0 & 0 & 0 \\
\hline $37.5 \mathrm{mg} \mathrm{m}^{-2}$ twice weekly & 3 & 0 & 0 & 0 & 0 & 0 & 0 \\
\hline $50 \mathrm{mg} \mathrm{m}^{-2}$ twice weekly & 7 & 0 & 0 & 0 & 3 & 0 & 0 \\
\hline $62.5 \mathrm{mg} \mathrm{m}^{-2}$ twice weekly & 6 & 0 & 0 & 1 & I & I & 1 \\
\hline $75 \mathrm{mg} \mathrm{m}^{-2}$ twice weekly & 2 & 0 & 0 & 1 & 0 & I & 0 \\
\hline
\end{tabular}




\section{Response rate and survival}

Although the aim of this study was not to provide data on these end points, we can report that 12 patients died within the first 2 months from the beginning of treatment and 11 patients were alive more than 5 months later. There were two treatment-related deaths at the two higher dose levels. Of the 13 patients who were alive at 2 months, 11 had a repeated radiological evaluation of their metastatic brain disease. One patient with metastatic rectal cancer showed a complete response (gemcitabine dose $50 \mathrm{mg} \mathrm{m}^{-2}$ ), six patients partial response (four at low doses of gemcitabine, one at $62.5 \mathrm{mg} \mathrm{m}^{-2}$ and one at the $75 \mathrm{mg} \mathrm{m}^{-2}$ level). In total, three patients had stabilisation of their brain disease.

\section{DISCUSSION}

The results of our phase I study of WBRT with gemcitabine used in a twice weekly schedule as a radiosensitiser in cancer patients with $\mathrm{BM}$ is presented.

Gemcitabine was chosen for this study, as it is a potent radiosensitiser in vitro and in vivo. The retention of the cytotoxic gemcitabine diphosphate (dFdCTP) in cells with a terminal elimination time as long as $72 \mathrm{~h}$ is probably a major factor determining this property. The radiosensitisation usually occurs under conditions where cancer cell lines demonstrate a concurrent redistribution in $S$ phase. At this point, depletion of dATP pools (due to ribonucleotide reductase inhibition produced by the drug) leads to misincorporation and misrepair of incorrect bases after radiation (McGinn and Lawrence, 2001; Lawrence et al, 2003). It has also been suggested that apoptosis contributes to the radiosensitisation of gemcitabine (Lawrence et al, 2001).

These conditions can be reproduced by (i) a long $(24 \mathrm{~h})$ exposure to a low concentration of gemcitabine $\left(10 \mathrm{nmol}^{-1}\right)$ or (ii) by a brief 2 -h treatment with higher but clinically relevant concentrations $\left(100 \mathrm{nmol}^{-1} 1-3 \mu \mathrm{mol}^{-1}\right.$ ) (Lawrence et al, 1997). In the second situation, radiosensitisation can be detected $4 \mathrm{~h}$ after treatment and can last for 2 days. It is suggested that the active metabolite dFdCTP needs to be present at the time of radiation to potentiate the radiation effects. A twice weekly dosing therefore or a slower rate infusion $\left(10 \mathrm{mg} \mathrm{m}^{-2} \mathrm{~min}^{-1}\right)$ are likely to be preferable as radiosensitisation strategies.

The administration schedule has a profound effect on the gemcitabine dose. This probably again relates to the fact that incorporation of the active metabolite dFdCTP is a saturable process with a prolonged intracellular retention time.

A weekly $30 \mathrm{~min}$ infusion can be dosed to up to $2.200 \mathrm{mg} \mathrm{m}^{-2}$. Currently, the clinical use of gemcitabine as a weekly single agent is between 1000 and $1250 \mathrm{mg} \mathrm{m}^{-2}$. Changing the schedule to twice weekly dosing at the same infusion rate reduces the dose per administration by an order of magnitude. The MTD for twice weekly dosing for $30 \mathrm{~min}$ infusions was $65-90 \mathrm{mg} \mathrm{m}^{-2}$ (Poplin et al, 1992; Lund et al, 1994). Interestingly, a review of safety and efficacy data of all European and US studies comparing twice weekly to weekly administration concluded that the actual response rates were similar (Martin et al, 1996). However, the twice weekly schedule was not recommended for general use as the reviewers concluded that it caused more 'flu like' side-effects (63.3 vs 19.8\%).

We have demonstrated that gemcitabine on a twice weekly schedule with WBRT can be given at a dose of $50 \mathrm{mg} \mathrm{m}^{-2}$. This dose is lower than that reported for single agent gemcitabine $\left(90 \mathrm{mg} \mathrm{m}^{-2}\right.$ ), probably due to the radiotherapy effect despite the fact that the axial skeleton was not irradiated. Similarly to our study, the addition of radiotherapy (to the abdomen for pancreatic cancer) reduced the twice weekly dose further to $40 \mathrm{mg} \mathrm{m}^{-2}$ (Blackstock et al, 1999). These investigators administered gemcitabine for 5 weeks and the fractionation schedule was $45 \mathrm{~Gy}$ in $1.8 \mathrm{~Gy}$ daily fractions with a further $5.4 \mathrm{~Gy}$ boost. Interestingly even the dose of $60 \mathrm{mg} \mathrm{m}^{-2}$ used by Blackstock et al (1999) had relatively modest toxicity (only grade 3 bone marrow toxicity noted). In our case, the dose of $62.5 \mathrm{mg} \mathrm{m}^{-2}$ had at least one case of severe toxicity. Both in this study and our study, platelet count reduction was the most common toxicity. Although we saw no nonhaematological toxicity, it has to be noted that other studies have shown that depending on the area of irradiation this should be expected. In a study of weekly gemcitabine in head and neck cancer patients (Eisbruch et al, 2001), the DLT was severe mucosal and pharyngeal toxicity while in patients with NSCLC DLT was oesophagitis and pulmonary actinic interstitial disease (Trodella et $a l, 2002)$. We noticed no deterioration in mental function as tested by the Felstein test that could be attributed to treatment despite having patients alive at 15 and 17 months. Nevertheless the majority of the patients had short survival, therefore strong conclusions about potential remote neurological toxicity cannot be drawn especially without a randomised control group for comparison. In contrast to the study by Martin et al (1996), we saw no evidence of prominent flu-like symptoms in any of our patients. We have to note, however, that our patients were on high dose (median dose of $12 \mathrm{mg} \mathrm{day}^{-1}$ ) of dexamethasone which may have abrogated this side effect.

To date a number of potential radiosensitising agents such as metallotexaphyrins, synthetic allosteric modifiers of haemoglobin or other chemotherapeutic drugs have been used without a demonstrable improvement in survival of patients with BM (Komarnicky et al, 1991; Phillips et al, 1995; Mehta et al, 2003). Therefore, the investigation of newer promising agents needs to continue.

It would not be safe to reach any conclusions about the efficacy of the addition of gemcitabine as a radiosensitiser to the WBRT. The 44\% 5-month survival observed needs to be challenged in a future phase III study comparing the combination with WBRT alone.

We have therefore defined that the MTD of gemcitabine at this schedule in patients with BM is $62.5 \mathrm{~m}^{-2}$, and a phase II study with gemcitabine given twice weekly at the preceding dose level of $50 \mathrm{mg} \mathrm{m}^{-2}$ as a radiosensitiser to WBRT is already in progress at our centre.

\section{ACKNOWLEDGEMENTS}

Eli-Lilly Corporation provided free gemcitabine. Support was also provided by the Postgraduate Medical Institute of the University of Hull in association with the Hull and York Medical School. We thank the Hull Cancer Unit Trials office and specifically Marie Hancock, Trevor Thompson, Karen Shepherd, Sarah Moffat, Suzie Bunton, Kirstie Smith, Ian Collins and Carol Tempest for their hard work and their support of this study.

\section{REFERENCES}

Blackstock AW, Bernard SA, Richards F (1999) Phase I trial of twice-weekly gemcitabine and concurrent radiation in patients with advanced pancreatic cancer. J Clin Oncol 17: 2208-2212

Carmichael J (1998) The role of gemcitabine in the treatment of other tumours. Br J Cancer 78(Suppl 3): S21-S25

Ceribelli A, Gridelli C, De Marinis F, Fabi A, Gamucci T, Cortesi E, Barduagni M, Antimi M, Maione P, Migliorino MR, Giannarelli D, Cognetti F (2003) Prolonged gemcitabine infusion in advanced non-small cell lung carcinoma: a randomized phase II study of two different schedules in combination with cisplatin. Cancer 98: 337-343 
Eisbruch A, Shewach DS, Bradford CR, Littles JF, Teknos TN, Chepeha BD, Marentette LJ, Terrell JE, Hogikyan ND, Dawson LA, Urba S, Wolf GT, Lawrence TS (2001) Radiation concurrent with gemcitabine for locally advanced head and neck cancer: a phase I study and intracellular drug incorporation study. J Clin Oncol 19: $792-799$

Folstein MF, Folstein SE, McHugh PR (1975) 'Mini-mental state'. A practical method for grading the cognitive state of patients for the clinician. Psych Res 12: $189-198$

Gridelli C, Perrone F, Gallo C, Rossi A, Barletta E, Barzelloni ML, Creazzola S, Gatani T, Fiore F, Guida C, Scognamiglio F (1999) Single-agent gemcitabine as second-line treatment in patients with advanced non small cell lung cancer (NSCLC): a phase II trial. Anticancer Res 19: $4535-4538$

Komarnicky LT, Phillips TL, Martz K, Asbell S, Isaacson S, Urtasun R (1991) A randomized phase III protocol for the evaluation of misonidazole combined with radiation in the treatment of patients with brain metastases (RTOG-7916). Int J Radiat Oncol Biol Phys 20: 53-58

Lagerwaard FJ, Levendag PC, Nowak PJ, Eijkenboom WM, Hanssens PE, Schmitz PI (1999) Identification of prognostic factors in patients with brain metastases: a review of 1292 patients. Int J Radiat Oncol Biol Phys 43: $795-803$

Lawrence T, Blackstock W, McGinn C (2003) The mechanism of action of radiosensitization of conventional chemotherapeutic agents. Semin Radiat Oncol 13: 13-21

Lawrence TS, Davis MA, Hough A, Rehemtulla A (2001) The role of apoptosis in $2^{\prime}, 2^{\prime}$-difluoro- $2^{\prime}$-deoxycytidine (gemcitabine)-mediated radiosensitization. Clin Cancer Res 7: 314-319

Lawrence TS, Eisbruch A, Shewach DS (1997) Gemcitabine-mediated radiosensitization. Semin Oncol 24(Suppl 7): S24-S28

Lund B, Ryberg M, Meidahl Petersen PM, Anderson H, Thatcher N, Dombernowsky P (1994) Phase II study of gemcitabine $\left(2^{\prime}, 2^{\prime}\right.$ difluorodeoxycytidine) given as a twice weekly schedule to previously untreated patients with non-small cell lung cancer. Ann Oncol 5: $852-885$

Martin C, Lund B, Anderson H, Thatcher N (1996) Gemcitabine: onceweekly schedule active and better tolerated than twice-weekly schedule. Anticancer Drugs 7: 351-357

McGinn CJ, Lawrence TS (2001) Recent advances in the use of radiosensitizing nucleosides. Semin Radiat Oncol 11: 270-280
Mehta MP, Rodrigus P, Terhaard CH, Roa A, Suh J, Roa W, Souhami L, Bezjak A, Leibenhaut M, Komaki R, Schultz C, Timmerman R, Curran W, Smith J, Phan SC, Miller RA, Renschler MF (2003) Survival and neurologic outcomes in a randomized trial of motexafin gadolinium and whole-brain radiation therapy in brain metastases. J Clin Oncol 21: 2529-2536

Patchel R (2003) The management of brain metastases. Cancer Treat Rev 29: $533-540$

Phillips TL, Scott CB, Leibel SA, Rotman M, Weigensberg IJ (1995) Results of a randomized comparison of radiotherapy and bromodeoxyuridine with radiotherapy alone for brain metastases: report of RTOG trial 89-05. Int J Radiat Oncol Biol Phys 33: 339-348

Poplin EA, Corbett T, Flaherty L, Tarasoff P, Redman BG, Valdivieso M, Baker L (1992) Difluorodeoxycytidine (dFdC)-gemcitabine: a phase I study. Invest New Drugs. 10: 165-170

Postmus PE, Haaxma-Reiche H, Smit EF, Green HJ, Karnicka H, Lewinski T, van Meerbeeck J, Clerico M, Gregor A, Curran D, Sahmoud T, Kirkpatrick A, Giaccone G (2000) Treatment of brain metastases of small-cell lung cancer: comparing teniposide and teniposide with wholebrain radiotherapy - a phase III study of the European Organization for the Research and Treatment of Cancer Lung Cancer Cooperative Group. J Clin Oncol 18: 3400 - 3408

Robinet G, Thomas P, Breton JL, Lenna H, Gouva S, Dabouis G, Bennouna J, Souquet PJ, Balmes P, Thiberville L, Fournel P, Quoix E, Riou R, Rebattu P, Perol M, Paillotin D, Mornex F (2001) Results of a phase III study of early versus delayed whole brain radiotherapy with concurrent cisplatin and vinorelbine combination in inoperable brain metastasis of non-small-cell lung cancer: Group Francais de Pneumo-Cancerologie (GFPC) Protocol 95-1. Ann Oncol 12: 59-67

Therasse P, Arbuck SG, Eisenhauer EA, Wanders J, Kaplan RS, Rubinstein L, Verweij J, Van Glabbeke M, van Oosterom AT, Christian MC, Gwyther SG (2000) New guidelines to evaluate the response to treatment in solid tumors. J Natl Cancer Inst 92: 205-216

Trodella L, Granone P, Valente S, Turriziani A, Macis G, CorboGM, Margaritora S, Cesario A, D'Angelillo RM, Gualano G, Ramella S, Galetta D, Cellini N (2002) Phase I trial of gemcitabine and concurrent radiotherapy in patients with inoperable non small cell lung cancer. I Clin Oncol 20: 804-810

Van den Bent MJ (2003) The role of chemotherapy in brain metastases. Eur J Cancer 39: 2114-2120 